\title{
INSUBORDINAÇÃO CRIATIVA COMO PARTE DO LEGADO CIENTÍFICO DE BEATRIZ SILVA D'AMBROSIO
}

\section{JOSÂNE GERALDA BARBOSA}

https://orcid.org/0000-0002-1958-4902

Instituto Federal de Minas Gerais

\section{CELI ESPASANDIN LOPES}

http://orcid.org/0000-0001-7409-2903

Universidade Cruzeiro do Sul/Universidade Cidade de São Paulo

Neste artigo apresentamos um recorte dos estudos de uma tese de doutorado em que estamos construindo a biografia intelectual de Beatriz Silva D’Ambrosio. Considerando o método biográfico, especialmente os estudos de Clandinin e Connelly, Dominicé, Dosse, Ferrarotti, Finger e Nóvoa, Lani-Bayle, Passeggi e Clementino e Pujadas Muñoz, abordam-se aqui os assuntos que constituem parte do legado científico da biografada para a Educação Matemática brasileira: as discussões sobre a insubordinação criativa na prática do professor e do pesquisador. São apresentadas algumas narrativas que elucidam a insubordinação criativa na concepção de Beatriz como um conceito que sensibiliza os profissionais para entender o outro e o contexto em que está inserido, honrar o compromisso assumido no exercício das atividades diárias, mobilizar saberes de forma a proteger a integridade dos estudantes e dos espaços formativos, neutralizar os efeitos desumanizadores da autoridade burocrática.

Palavras chave: Beatriz Silva D’Ambrosio. Insubordinação criativa. Subversão responsável. Educação Matemática.

This paper presents a preliminary view resulting from a doctoral thesis aimed at assembling the intellectual biography of Beatriz Silva D'Ambrosio. Supported by the biographical method, especially in the studies of Clandinin and Connelly, Dominicé, Dosse, Ferrarotti, Finger and Nóvoa, Lani-Bayle, Passeggi and Clementino and Pujadas Muñoz, the text deals with the issues that constitute part of the sci- 
entific legacy of that scholar for Brazilian mathematics education; specially discussions about creative insubordination in the practice of teachers and researchers. Creative insubordination is presented according to Beatriz's view, This concept describes the willingness of professionals to understand others and the context in which they are inserted, honor the commitment assumed while conducting their daily activities, mobilize knowledge in order to protect the integrity of students and training spaces, as well as neutralize the dehumanizing effects of bureaucratic authority.

Keywords: Beatriz Silva D'Ambrosio. Creative Insubordination. Responsible Subversion. Mathematical Education.

\section{RESUMEN INSUBORDINACIÓN CREATIVA COMO PARTE DEL LEGADO CIENTÍFICO DE BEATRIZ SILVA D'AMBROSIO}

En este artículo presentamos un recorte de los estudios de una tesis doctoral en la que estamos construyendo la biografía intelectual de Beatriz Silva D’Ambrosio. Apoyados en el método biográfico, especialmente en los estudios de Clandinin y Connelly, Dominicé, Dosse, Ferrarotti, Finger y Nóvoa, Lani-Bayle, Passeggi y Clementino y Pujadas Muñoz, tratamos aquí los temas que forman parte del legado científico de la biografía a la Educación Brasileña de Matemáticas: las discusiones sobre la insubordinación creativa en la práctica del profesor y el investigador. Se presentan algunas narrativas que elucidan la insubordinación creativa en la concepción de Beatriz como un concepto que lleva a los profesionales a entender al otro y al contexto en donde está inscrito, para honrar el compromiso asumido en el ejercicio de las actividades diarias, para movilizar el conocimiento con el fin de proteger la integridad de los estudiantes y los espacios de formativos y a neutralizar los efectos deshumanizadores de la autoridad burocrática.

Palabras clave: Beatriz Silva D’Ambrosio. Insubordinación Creativa. Subversión responsable. Educación Matemática.

\section{Introdução}

Neste artigo expomos parte de um estudo biográfico, em que tomamos o indivíduo em sua singularidade e usamos as narrativas de outras pessoas que, tendo convivido com o biografado, narram experiências que nos permitem reconstruir sua trajetória - neste caso, o percurso profissional de uma professora pesquisadora -, para evidenciar suas contribuições para o desenvolvimento de uma área de conhecimento. Assim, assumimos na pesquisa o método biográfico, que se refere às histórias da vida, às reconstruções biográficas através de relatos, de narrativas de outras pessoas e de outras fontes complementares (PUJADAS MUÑOZ, 1992). 
Apresentaremos um recorte dos estudos de uma tese de doutorado em que estamos construindo a biografia intelectual de Beatriz Silva D'Ambrosio, carinhosamente chamada de Bia, apelido que muito a agradava e, por isso, optamos por nos referir a ela dessa forma.

Filha de Maria José Silva D'Ambrosio e de Ubiratan D'Ambrosio, Bia nasceu em 26 de janeiro de 1960, na cidade de São Paulo. Iniciou a vida escolar nos Estados Unidos, onde viveu dos 3 aos 13 anos de idade. Retornando ao Brasil, concluiu o último ano do Ensino Fundamental no Colégio Progresso e cursou o Ensino Médio no Colégio Pio XII, ambos em Campinas, no interior de São Paulo. Fez licenciatura em Matemática na Universidade Estadual de Campinas (UNICAMP) e, nos dois últimos anos da graduação, também trabalhou no Centro de Educação - Orientação, Treinamento e Pesquisa (CeEduc), com crianças que apresentavam dificuldades de aprendizagem. Com essa primeira experiência docente, sentiu a necessidade de se aperfeiçoar na arte de ensinar Matemática. Visualizando essa possibilidade na área da Educação Matemática, não encontrou nenhum curso de pós-graduação no Brasil, o que a levou de volta aos Estados Unidos, onde cursou mestrado e doutorado na Indiana University Bloomington, de 1981 a 1987.

Deixemos que Bia lhes conte um pouco sobre essa etapa de sua vida:

Minha formação, como educadora matemática, começou com o curso de Matemática na Unicamp. Logo dei aula numa escola para crianças que tinham dificuldades de aprendizagem, e era uma escola que oferecia acompanhamento das crianças, além da escola. Nessa escola, os pais procuravam esse serviço de acompanhamento, para que a gente tentasse recuperar crianças que estavam indo mal na escola. E aí eu comecei a me interessar muito pelos motivos pelos quais as crianças iam mal na escola e achei que eu poderia ajudar muito mais se eu tivesse mais formação. Então eu fui atrás de fazer um mestrado na época, uma pós-graduação, e não existia no Brasil, a Educação Matemática. [...] Foi em 80 que eu saí, para fazer mais um pouco de formação, me especializar em problemas de aprendizagem. Na minha cabeça era isso que eu ia fazer. Aí eu cheguei aos Estados Unidos, escolhi um programa e comecei a fazer essa formação de pós-graduação e conhecer a área de Educação Matemática que aqui no Brasil ainda não se constituía como uma área de formação [não era ainda] não existia o curso de pós-graduação, não existiam revistas. Era o comecinho no Brasil, nos Estados Unidos já estava bem estabelecido. Então eu fui com a intenção de fazer mestrado e acabei ficando e fazendo o doutorado mesmo de vez, direto e conhecendo o mundo da pesquisa da Educação Matemática. (BRIÃO, 2015, p. 2) ${ }^{1}$

Retornando ao Brasil no segundo semestre de 1987, Bia lecionou na UNICAMP e na PUC-SP (Pontifícia Universidade Católica de São Paulo), instituições em que trabalhou na criação do primeiro curso noturno da UNICAMP, uma licenciatura em Matemática, e do primeiro curso de pós-graduação em Educação Matemática na PUC-SP.

Em 1989, regressou aos Estados Unidos, onde concentrou a maior parte de sua trajetória profissional, e trabalhou em quatro universidades norte-americanas: Indiana University (Bloomington, de 1981 a 1987), Purdue University Indianapolis (de 1994 a 2005), University of Delaware (de 1989 a 1992), University of Georgia (de 1992 a 1994) e Miami University (de 2005 a 2015). Em 2013, esteve no Brasil, quando trabalhou como professora visitante na Universidade Estadual Paulista Julio de Mesquita Filho (UNESP).

Mas, em setembro de 2015, faleceu nos Estados Unidos, vítima de um aneurisma cerebral. Após 37 anos de efetivo exercício em sala de aula, sendo 28 deles após a conclusão do doutorado, desenvolveu diversos trabalhos

1 Entrevista concedida a Gabriela Felix Brião, no XIV Congresso Interamericano de Educação Matemática (CIAEM), ocorrido no início de maio de 2015, na cidade de Tuxtla Gutierrez, no México. 
e pesquisas que deixaram grandes contribuições para as comunidades científicas brasileira e americana.

\section{O método biográfico}

Esta é uma pesquisa qualitativa, apoiada nas premissas do método biográfico, que, proveniente do campo da Sociologia, desde 1918 tem buscado seu espaço, inicialmente implementado nos estudos de Thomas e Znaniecki, da Escola de Chicago, que pesquisaram camponeses poloneses (LANI-BAYLE, 2008). Aparece como aporte epistemológico e metodológico opositor às práticas positivistas que imperavam nas pesquisas científicas pautadas na objetividade e na nomotetia. Possibilita uma abordagem qualitativa, com menor ênfase pragmática e maior valor científico atribuído à subjetividade dos sujeitos envolvidos nas pesquisas realizadas (DOMINICÉ, 2014; FERRAROTTI, 2014a; FERRAROTTI, 2014b).

A opção pelo método biográfico reside em sua possibilidade de sugerir e ilustrar melhor as informações, não apenas por utilizar-se da narrativa do sujeito biográfico - no caso desta pesquisa, narrativas escritas por Bia ao longo de sua vida -, mas também porque pode ser complementado pelas declarações das pessoas que constituem o ambiente social imediato, ao fornecerem novos fatos, relevantes para uma melhor compreensão do sujeito biografado.

Consideramos então as narrativas escritas por Bia e as narrativas escritas e orais de pessoas que dialogaram com ela durante seus processos de construção de conhecimentos, pautando-nos em Clandinin e Connelly (2011), que recomendam a pesquisa narrativa como forma de lembrar, construir, reconstruir e analisar fenômenos narrativos.

Ferrarotti (2014b) apresenta como essência fundamental a subjetividade e a antinomo- tetia, entendidas como a aceitação e a significação do sujeito historicamente constituído pelas relações sociais a que está exposto e gerador de materiais autobiográficos a serem valorizados no ato de biografização. Trata-se de um método cuja ênfase não envolve a quantificação, a experimentação, a objetivação e a comprovação ou refutação de hipóteses. Diferentemente, sua preocupação central é o processo pelo qual as pessoas se formam, as principais interferências nessa formação e a forma como elas compreendem e dão significado ao contexto em que vivem.

Por esta natureza, sua validade científica é constantemente contestada por pesquisadores que sustentam suas pesquisas em pilares mais tradicionais ou clássicos. E, recentemente, alguns pesquisadores, vêm modificando o método, ao utilizá-lo em suas investigações, não epistemologicamente, mas em suas técnicas de coleta, análise e apresentação dos dados, para que este novo método se adapte às condições impostas pela cientificidade positivista. Isso tem the conferido um empobrecimento heurístico considerável, pois tende a perder a sua essência criativa. Preocupações excessivas de pesquisadores e cientistas com a pragmatização dos procedimentos, a valorização da objetividade, a quantificação de fatos e situações e a generalização tendem a tornar as biografias documentos monótonos, pobres de significação e vida, caracterizando-se apenas como uma justaposição de personagens, fatos, acontecimentos e informações, apresentados de forma fragmentada e coisificada.

\footnotetext{
A biografia transforma-se frequentemente num relatório de acontecimentos, numa verdadeira ficha sociológica coisificadora. Vai-se ao ponto de voltar a escrever na terceira pessoa e num tom burocrático - sine ira nec studio, dizia $M$. Weber -, não a história de uma existência e uma existência humana, mas o seu esqueleto objetivado. (FERRAROTTI, 2014b, p. 39)
} 
Alguns trabalhos, como o de Franco Ferrarotti, em 1950, na Itália; o de Oscar Lewis, em 1961, no México; e o de Daniel Bertaux, em 1960, na França, começaram a retomar a essência do método biográfico, que consiste em compreender, por meio das histórias de vida, os sentidos que os atores sociais dão aos seus próprios atos. Entretanto, foi somente a partir dos anos de 1980 que ele foi amplamente utilizado e ganhou sua legitimidade nos diversos campos das ciências sociais (LANI-BAYLE, 2008).

Analogamente, uma bifurcação existente no método biográfico é apresentada por Passeggi e Souza (2017, p. 11), que denominam de "epistemologia do sul" e "epistemologia do norte". A primeira é vinculada a "um modo narrativo de pensar", cuja ênfase está centrada na construção histórica, na consideração ao literário e ao circunstancial e, ainda, conduz o autor/narrador por um caminho de conscientização, resistência e emancipação. A "epistemologia do norte" é associada a "um modo pragmático", de caráter hegemônico, colonial, dogmático e excludente, cuja ênfase se centra no lógico, no objetivo e no científico.

No Brasil, o método biográfico ganhou visibilidade e começou a ser utilizado a partir dos anos 2000, quando as pesquisas se voltavam para as histórias de vida ou para os memoriais autobiográficos. 0 ano de 2004 marcou a realização do primeiro Congresso Internacional de Pesquisa (Auto)Biográfica (CIPA), um espaço privilegiado para sistematizar as pesquisas (auto)biográficas, refletir e avançar nas demarcações teórica, metodológica e epistemológica do método, sobretudo para o campo da Educação. O número de pesquisadores e estudantes que compartilham os resultados de suas pesquisas e dialogam sobre os possíveis avanços no campo (auto)biográfico tem apresentado significativo aumento desde sua primeira edição.
Essa busca por uma hermenêutica própria, que envolva novas formas de compreender, conceber, produzir e analisar as fontes (auto) biográficas, nos conduz à necessidade de demarcar o método biográfico no campo da Educação. Um método que se apresenta com caráter "subjetivo, interpretativo, qualitativo e alheio aos esquemas de hipótese-verificação da perspectiva positivista" (PASSEGGI; SOUZA, 2017, p. 12).

Assim, o trabalho de biografia a ser desenvolvido na pesquisa que subsidia este artigo estará vinculado a um modo narrativo de pensar, libertado das abordagens tradicionais, propondo-se ao desafio de produzir uma biografia que apresente o legado teórico e metodológico da biografada, compreendendo seus processos formativos e o contexto em que viveu.

Além disso, consideraremos a construção da biografia numa perspectiva não historicista, em que há ruptura com a concepção de história como sucessão diacrônica ou temporal, cronológica. Propomo-nos a encontrar, portanto, as "convergências que emergem tematicamente nas histórias de vida singulares, dentro de um determinado horizonte histórico" (FERRAROTTI, 2014a, p. 51). Assim, a biografia a ser construída considerará os temas científicos abordados por Bia ao longo de sua trajetória profissional.

Finalmente, admitiremos o conceito da biografia intelectual, definido por Dosse (2015), ao produzir a biografia de Paul Ricoeur. Ela é assumida como o estudo da vida de escritores, filósofos e "homens de letras" em geral, entendidos como pessoas que "se deixam ler por suas publicações, não por seu cotidiano" (DOSSE, 2015, p. 361). Com isso, abordaremos o legado científico de Beatriz Silva D'Ambrosio, focalizando apenas a sua produção científica e profissional, sem nos atermos à sua vida familiar ou pessoal. Da mesma forma, participarão 
da pesquisa, como colaboradores, pessoas ligadas à vida profissional de Bia, ao seu campo intelectual.

A investigação tem se sustentado nas narrativas (auto)biográficas contadas por pesquisadores, alunos e professores de Bia, além da sua produção bibliográfica, por vezes individual e por vezes em coautoria. Portanto, tratase de uma biografia intelectual polifônica, entendida como uma construção da autora, dos colaboradores e da própria biografada, que nos fala por meio de sua produção científica. A biografia desloca-se de "uma busca exclusivamente centrada num indivíduo para uma busca plural" (DOSSE, 2015, p. 376).

Seguindo na contramão do método biográfico tradicional, que prioriza os materiais biográficos secundários, compostos por fotografia, laudos, livros, diários, correspondência, em detrimento dos chamados materiais biográficos primários, que são as narrativas autobiográficas, esta pesquisa prima pela subjetividade presente na narrativa de cada um de seus colaboradores. São narrativas, orais e escritas, solicitadas a diversos professores e pesquisadores que se envolveram profissionalmente com Bia. Como ela lecionou e desenvolveu pesquisas tanto no Brasil quanto nos Estados Unidos, estão sendo convidados a reportar as narrativas profissionais brasileiros e norte-americanos. Os brasileiros, por meio de relatos orais ou escritos; e os americanos, por relatos escritos.

As narrativas constituirão, portanto, artefatos de grande valor heurístico nesta jorna$\mathrm{da}$, fundamentais ao propósito de desvelar a educadora Beatriz Silva D'Ambrosio e suas contribuições para as comunidades científicas. São documentos inéditos, de riqueza incomensurável, produzidos especificamente para a pesquisa proposta, registros inexistentes em outros documentos. Dada a liberdade que uma narrativa (auto)biográfica apresenta, neles pode ser lida parte da história dos colaboradores e da biografada - momentos, personagens, contextos e circunstâncias das quais apenas eles se recordam e aos quais provavelmente atribuem a maior importância.

Assim, além das recorrências nas narrativas, também serão consideradas as singularidades pontuadas por cada colaborador. Fatos ocasionais relembrados indicam as especificidades vivenciadas por cada um deles com Bia, em momentos muito específicos de suas vidas, aos quais atribuíram maior significado, a ponto de serem relembrados. Portanto, procuraremos construir, por meio de vários olhares e mãos, a biografia intelectual polifônica desta educadora que constatamos tão querida por todos com quem conviveu.

Ademais, sobre a natureza das narrativas (auto)biográficas, admitimos a hermenêutica da interação que se faz presente no relacionamento entre pesquisador e colaborador, por meio de rememorização e reconstituição de fatos, personagens e acontecimentos do passado, que tangenciaram a trajetória profissional de Bia. Essas lembranças surgem no ato de narrar, são contadas e ponderadas pela ótica do presente e ressignificadas pelas experiências vivenciadas pelo colaborador até o momento da narrativa. Elas tendem a propiciar a reflexividade e a atribuição de sentido ao vivido pelos que narram; contam suas histórias; explicam as circunstâncias, o contexto, as atitudes e os personagens; e depois refletem sobre o relato produzido, gerando novos conhecimentos, além de promoverem a aproximação entre o pesquisador e o biografado e entre o pesquisador e os colaboradores.

Ao final da pesquisa esperamos ter conhecido e analisado os diversos temas estudados por Bia, concretizando, assim, a sua biografia intelectual. Do mesmo modo que Dosse (2015), sabemos que jamais concluiremos esta tarefa, não importa o número de fontes que consiga- 
mos reunir. Sempre haverá pessoas, temas e materiais não lidos, não ouvidos ou não sabidos. Entretanto, neste processo de ouvir os diversos narradores e suas histórias, ler a produção bibliográfica de Bia e refletir sobre ela, vamos desvelando essa educadora. Ambas, autora e biografada, que nunca se viram ou se falaram, vão se conhecendo gradualmente, dia após dia, e então se dará a produção da biografia, escrita por uma pesquisadora, sob a ótica de tantos outros.

Como se trata de uma pesquisa em andamento, neste artigo abordaremos um dos assuntos que acreditamos constituir parte do legado científico de Bia para a Educação Matemática brasileira: as discussões sobre a insubordinação criativa na prática do professor e do pesquisador.

\section{Insubordinação criativa}

São recentes, no contexto da Educação Matemática brasileira, as pesquisas que se propõem a identificar, refletir, significar e contextualizar a insubordinação criativa presente no ambiente escolar. Celi (segunda autora deste artigo) e Bia foram as primeiras pesquisadoras a utilizar este conceito, associado ao de subversão responsável, como sinônimos, na prática tanto de professores quanto de pesquisadores.

Ao estudar o comportamento desviante presente nas estruturas sociais burocráticas, em 1963, Robert King Merton apresentou algumas ideias, no campo da Sociologia, que se aproximam do conceito de insubordinação criativa. Na área da Nutrição, em 1967, surgiu outro conceito similar, chamado "desvio positivo". Com significado também semelhante, a subversão responsável apareceu no campo da Enfermagem, em pesquisa realizada por Hutchinson. Mas foi no final da década de 1970 e no início de 1980, no campo da Etnografia, que nasceu o conceito nomeado “insubordinação criativa", quando Crowson e Morris analisaram atitudes insubordinadas de 16 diretores de escolas da cidade de Chicago.

Na área da Educação, em 1992, Keedy e, em 1995, Haynes e Licata realizaram pesquisas similares, também envolvendo diretores de escolas. E, no campo da Educação Matemática, a pesquisadora norte-americana Rochelle Gutiérrez, em 2013, foi a primeira a utilizar o conceito na área de Educação Matemática, ao discutir ações de professores de Matemática quando resistem a políticas e diretrizes burocráticas, em um contexto que envolve questões sobre racismo, classe e linguagem. Ela estudou como alguns professores dessa área assumem riscos em seus contextos de trabalho para defender alunos historicamente marginalizados.

Celi e Bia começaram a dialogar com o conceito em janeiro de 2014, quando escreveram o primeiro artigo publicado no Boletim de Educação Matemática (Bolema) em abril de 2015 (D'AMBROSIO; LOPES, 2015a). Ao discutirem as ações de insubordinação criativa, estabeleceram conexões com a perspectiva freiriana e consideraram que ser subversivamente responsável requer assumir-se como ser inconcluso e ter consciência sobre quando, como e por que agir contra procedimentos ou diretrizes estabelecidas no âmbito profissional.

É tomar a curiosidade como alicerce da produção de conhecimento e fazer de seu inacabamento um permanente movimento de busca. Nesse artigo elas fazem à comunidade de educadores matemáticos (professores e pesquisadores) um convite para debater as ideias de insubordinação criativa em suas produções.

A partir daí, elas deram início à Coleção Insubordinação Criativa na Editora Mercado de Letras: redigiram o primeiro volume e convidaram pesquisadores para produzirem capítulos para o segundo volume, nos quais evidenciassem relações de suas produções científicas 
com a insubordinação criativa. Ao mesmo tempo, convidaram professores pesquisadores a redigirem capítulos para um terceiro volume, no qual discutiriam suas práticas pedagógicas diante do conceito.

Apesar da dificuldade para separar a produção científica de Bia e de Celi sobre o conceito de insubordinação criativa, por ter a produção sido escrita pelas duas em sua quase totalidade, concentraremos nossa atenção na repercussão da produção de Bia na comunidade científica brasileira. Após o seu falecimento, Celi e outros profissionais com quem Bia trabalhou seguem investigando e divulgando o conceito entre os pesquisadores brasileiros.

Alguns educadores matemáticos brasileiros, colombianos e americanos se uniram para criar uma conferência internacional sobre a insubordinação criativa em educação matemática (International Conference on Creative Insubordination in Mathematics Education ICOCIME). A primeira edição ocorreu em 2017, em São Paulo, na Universidade Cidade de São Paulo (UNICID) e a segunda, em 2019, na Universidade de Santa Catarina (UFSC), em Florianópolis. Ambos os eventos demarcaram um local privilegiado de diálogo e de muito aprendizado. Professores e pesquisadores de diferentes países e instituições participaram com pesquisas que dialogavam com o conceito de insubordinação criativa, socializaram suas investigações, inquietações e contribuíram para o crescimento do conceito e o fortalecimento de suas raízes: compromisso com a justiça social e com a formação do sujeito crítico e ético.

O ICOCIME 1 contou com apresentação de pôsteres, palestras, mesas-redondas e workshops. Ainda, foram constituídos grupos de discussão para abordar as abrangências e as implicações da insubordinação criativa: Insubordinação Criativa em pesquisas em Educação Matemática, Insubordinação Criativa nas práticas pedagógicas, Insubordinação Criativa na aprendizagem matemática, Insubordinação Criativa no currículo de Matemática e Insubordinação Criativa na avaliação de Matemática. Não foram produzidos anais do evento, mas as produções foram publicadas em uma edição temática da revista REnCiMa.

No ICOCIME 2, foram apresentados pôsteres, comunicações científicas; houve rodas de conversa, minicursos, palestras e mesas-redondas. Para esse evento foram produzidos anais, e os autores foram incentivados a expandir seus textos e submetê-los à edição temática do International Journal for Research in Mathematics Education (RIPEM).

As discussões iniciadas por Bia em relação à Insubordinação Criativa ecoaram fortemente nesses espaços. 0 conceito vem sendo amplamente utilizado pela comunidade de educadores matemáticos, seja em suas atividades docentes, seja em suas produções científicas.

Nas edições do ICOCIME, houve momentos de homenagem à professora pesquisadora. À época do primeiro ICOCIME, compôs-se uma mesa com um dos professores de Bia, da UNICAMP, o professor Sergio Lorenzato; uma de suas alunas, também da UNICAMP, a professora Regina Célia Grando; um pesquisador que fez pós-doutorado com Bia nos Estados Unidos, o professor Vicente Marafioti Garnica; e as filhas dela, Gabriela e Rafaela. Em suas falas, percebeu-se o quanto Bia foi especial e marcante na vida daqueles com quem conviveu. Ponderaram a sua dedicação, a confiança que depositava em seus alunos, a sua capacidade de problematizar, encorajar e empoderar as pessoas. Ressaltaram a sua grande humildade, pois ela nunca se apegou a seus títulos. Isso não era importante, e ela não aceitava ser considerada por seu título. Gostava de ser chamada simplesmente por Bia e ensinou suas filhas que o mais importante, a parte mais linda da vida, era ajudar as outras pessoas. 
Também nesse primeiro ICOCIME, as suas filhas, Gabriela e Rafaela, fizeram uma apresentação, em que ressaltaram algumas provocações que aprenderam com a mãe e que são facilmente encontradas nos textos dela ${ }^{2}$.

A primeira observação é que a habilidade especial de apresentar excelentes ideias todo mundo tem. Todo mundo nasce com essa habilidade natural, e a segunda coisa é a coragem de agir nessas ideias. Então, com essas duas coisas você pode conseguir ter uma confiança criativa e agir com essa confiança criativa. Nossos pensamentos e opiniões se baseiam no tempo em que passamos aqui no Brasil. Cada uma de nós ficou um ano estudando, no Ensino Médio, em escolas privadas em Tatuí, eu, e em Rio Claro, a Gabi. O resto da nossa experiência educacional tem sido em escolas públicas e particulares nos Estados Unidos, e estudando educação a nível universitário. Nossas curiosidades sobre o sistema educativo foram adotadas por nossa mãe que acreditava que independentemente de limitações do governo a insubordinação criativa na sala de aula iria beneficiar o aluno por toda a vida. Temos aí uma foto de uma sala de aula onde os meninos estão bem aborrecidos. No Brasil, em matemática, existem muitas regras: "não levante a sua mão em sala de aula", "não questione os seus professores", "faça o que te dizem, quando te mandem e do jeito que o professor disse". Minha mãe não acreditava nessa ideologia. Seu foco principal, no trabalho dela, foi que havia sempre uma outra maneira de resolver o mesmo problema e que as regras foram feitas para serem quebradas. Quando se trabaIha em sala de aula a Bia encorajaria: "Eu amo a sua ideia!", ela falava para os seus alunos. "Diga-me porque que ela funciona?". Nestes momentos, quando os alunos encontram a sua própria maneira de resolver os problemas dificeis. Ela habilitava os alunos, tornando-os animados para aprender Matemática e ansiosos por aprender mais. Bia deu autonomia aos alunos. Ela queria que eles sentissem que estavam no comando e assim fazia com que os alunos com quem trabalhou começassem a amar de matemática. Não havia regras para Bia. Que-

2 Palestra apresentada no evento, com ajuda de recurso audiovisual. brando as regras, dizia ela, é o que nos faz crescer e aprender verdadeiramente. Esta ideia é o centro da insubordinação criativa. Essencialmente, ela leva-nos a quebrar as normas e agitar um pouco as coisas. Mas ser criativamente insubordinado é dificil e como vamos saber, por onde começar? Vamos primeiro olhar para as salas de aula e a maneira em que operam atualmente. A tradição diz que as crianças odeiam matemática, mas são obrigadas a estudar pensando apenas em se sair bem no Enem. Bia não teria aceitado a ideia de que não é importante que as crianças gostem de Matemática, enquanto aprendem matemática. É nosso trabalho, enquanto professores, entregar o material para os alunos de forma que eles sejam receptivos ao material, para que eles realmente entendam, para que sejam receptivos eles devem desfrutar o conteúdo. Então, se isso significa que nós devemos disfarçar a matemática em formas de jogos, deixem eles jogarem os jogos. Se isso significa explorar e criar, deixem que eles explorem e criem. Por outro lado, se um aluno quer resolver os problemas de um livro, então deixe-o resolver. As crianças não são feitas para odiar a matemática. Como você pode odiar algo que não compreende? Eles simplesmente não gostam de Matemática porque todas as experiências que tiveram com a Matemática têm sido negativas. A maioria das crianças odeiam a Matemática porque eles odeiam a repetição e eles odeiam se sentir frustrados. Também porque na escola os professores sempre os empurram para passar para o próximo nível antes que eles estejam prontos. Quando fazem isso o estudante começa a falhar e assim a sua confiança na Matemática é destruída. Você não pode mudar as experiências passadas por eles, mas você pode fazer boas e novas experiências. Estamos tão acostumados a fazer as coisas como elas sempre foram feitas que esquecemos que cada criança aprende de uma forma diferente. Palestras durante as aulas e fazendo exercícios de livros não são suficientes para todos os alunos. Para os que odeiam Matemática estamos ensinando-os a odiá-la. Mas, estudos quase sempre garantem que esses estudantes irão pior em Matemática do que aqueles que gostam de Matemática, alterando o nosso foco para ajudar cada aluno, orientando-os de uma forma que eles são re- 
ceptivos e que gostam. Então poderemos ver melhorias vastas no desenvolvimento da criança. Bia acreditava que um professor nunca deve ser um palestrante, mas um facilitador e guia que apresente apoio para cada criança através da sua própria exploração da Matemática. Alunos da Bia, frequentemente, cresceram frustrados com sua resposta às suas perguntas, porque os alunos sempre perguntavam: "Isso é certo? Isso funciona?" E ela respondia: "Não tenho certeza, porque você não me diz? Mostre-me o que você fez, me explique porque você acha que é certo ou não está certo?" Ao fazer isto, cada estudante tornou-se o seu professor. As perguntas mostraram falta de confiança em si mesmos. Mas fazendo-os responder as suas próprias perguntas, empurrou-os para crescer em sua confiança na Matemática e lentamente a começar a gostar mais de Matemática. E se o aluno estava errado? Bem, então durante a explicação do seu trabalho a Bia salientava a eles que não fazia sentido e com isso os empurrava pensar mais sobre seus próprios processos matemáticos. Os alunos ficavam frustrados com suas perguntas à Bia, pois seu silêncio em dar respostas e dizer se eles estavam certos ou errados, porque eles não estavam habituados a isso na sala de aula. Eles foram acostumados a ter uma resposta correta e para a professora passar dizendo: "Ah, bom trabalho!" No entanto Bia utilizou essa técnica muito simples para ser criativamente insubordinada: fez perguntas em vez de dar respostas. Ela agia como guia para que os alunos descobrissem coisas sozinhos, ajudando-os a criar uma base sólida de compreensão verdadeira. Bia valorizava a liberdade em sala de aula para cada criança explorar, descobrir, aprender e sentir-se como um mini gênio. Todo problema tem mais de um caminho certo para chegar a resposta, especialmente na Matemática. Não deve ter uma solução determinada pela professora. Deixe-me te fazer uma pergunta: De quantas maneiras você pode fazer o número oito? Pense nisso por um segundo. $1+$ $7,2+6,3+5$ e $4+4$ e também $10-2,12-4$, todos eles fazem o 8. Mas é só isso? Não! $2 \times 2+4 \times 1$ também funciona. As possibilidades são ilimitadas! Deixar as crianças a explorar permite que elas se sintam como gênios, lhes permitem aprender a amar a Matemática e lhes permite colaborar as ideias com os outros. Nos Estados
Unidos fazemos esses tipos de exercícios todos os dias com as crianças na esperança de ampliar a sua visão de Matemática e empurrando -os para explorar. Colocando uma questão sem uma resposta pré-determinada ou sem uma solução específica que você está procurando é uma maneira de ser criativamente subordinado. Minha mãe, minha irmã e eu entendemos que ao seguir os passos de Bia e usando insubordinação criativa na sala de aula é realmente dificil. Mas nós estamos dando a vocês quatro exemplos de como fazer isso. Deixe os alunos perguntarem qualquer coisa e torne-os seus próprios professores. Dar aos alunos uma voz na sala de aula. Deixe os alunos explorarem o que deixe eles curiosos. Solte-se da ideia de que deve haver uma única resposta para cada problema. Em outras palavras, o primeiro passo de ser criativamente insubordinado é aceitando, permitindo e até mesmo incentivando a criatividade dos seus alunos. Abrindo mão da ideia de que não há uma maneira certa de fazer alguma coisa e dar aos seus alunos uma voz em sala de aula. Ao fazer isso você começou o processo de modificação de suas práticas para ser criativo, para ser diferente e para ser interessante para os alunos. Aqui estão algumas outras coisas que são importantes para se lembrarem na sala de aula e que são importantes a considerar em ser criativamente insubordinado. Primeiro, ouça para compreender e não para responder. Esta é uma prática recomendada quando consideramos que aprendemos as necessidades dos outros, não só na Matemática. Dê a cada aluno uma voz e uma chance de dizer o que ele sabe, antes de repreendê-lo pelo que ele não sabe. É nosso trabalho, como educadores, aprender de nossos alunos. Construindo relações estáveis e desconfiança com eles vai mudar tudo para você e para eles. Quando a Gabi estudava aqui no Brasil ela notou um forte contraste presente na sala de aula para professores que tinham fortes relações com os seus alunos contra aqueles que não tinham. Quando um professor que respeitava-nos entrava na sala de aula, todo mundo ria e brincava. E nos momentos que ele dizia: "E aí, vamos aprender alguma coisa?" A sala crescia em silêncio e ele ensinava facilmente. Criando uma relação com os nossos alunos, cria confiança e cria um espaço para cada estudante se sentir seguro para fazer per- 
guntas e aprender. Deixe-os sentirem-se seguros, confiantes e com suporte assim eles vão querer trabalhar e aprender. Então, o que isso significa para nós? O que é a grande figura? Temos que preparar nossos alunos para o mundo real. Parece haver divisões claras entre os sujeitos do Ensino Fundamental e os da pós-graduação. No mundo real, na aplicação da vida, todos os materiais diferentes que estudo na escola interagem se relacionam entre si. Quando um elemento está ausente há uma falta de desenvolvimento em tudo. A criança e o aluno holístico é onde devemos concentrar e é o futuro da educação nos Estados Unidos e aqui no Brasil, independente da política educacional. Muitas vezes encontramos alunos em sala de aula que são capazes de memorizar fatos, a fim de reproduzir respostas que são todas iguais, mas quando são pedidos para aplicarem os mesmos conceitos para um problema do mundo real eles são incapazes de fazê-lo, afirmando que eles nunca realmente aprenderam isso. Gastamos horas para certificarmos de que nossos alunos sabem $5 \times 8$ e $7 \times 9$, mas quando perguntam quantos biscoitos devemos comprar para uma festa que queremos que cada criança tenha quatro biscoitos e existiam 22 crianças na sala de aula, elas tornam-se incapazes de calcular. Crianças, como adultos, não gostam de fazer as coisas quando não veem um propósito nelas. Quando perdemos a ligação entre a Matemática e o mundo real os alunos pensam em Matemática como um conceito obsoleto, abstrato, que não tem sentido para elas e então eles não gostam. Ligando-a ao mundo real, ao mundo deles, nós criamos uma conexão entre eles e a Matemática e os conceitos não parecem tão abstratos. Na educação interdisciplinar, fundada em valores de justiça social e pedagógica, devem se entrelaçar ao material escolar com aplicação no mundo real. Então aqui eu tenho uma foto de uma criança, de um desenho que uma criança fez, que é feito da cabeça dela, das experiências que ela tinha. Mas, embaixo, esses risquinhos, é uma foto dos pássaros em um livro de Matemática, em que o aluno aprende a contar. Depois desse estudo viu a estudante começou a desenhar os pássaros assim3. Ela perdeu o conceito

3 A foto inicial mostra um pássaro desenhado com os detalhes observados pela criança. Abaixo, exibe a figura que consta no livro, o desenho de pássaros de criatividade, porque ela estava aprendendo com materiais que não eram criativos. Este é um gráfico que mostra os resultados dos estudos de vários pesquisadores que já fizeram estes mesmos estudos por várias vezes, nos Estados Unidos e no mundo inteiro. Eu queria mostrar para vocês que o resultado é sempre igual. Por exemplo, em 1968, o George Lent e Bem Jamen fizeram um estudo sobre criatividade com crianças de 5 anos. Fizeram uma série de perguntas, que agora nos Estados Unidos eles usam para testar as crianças. E $98 \%$ dos alunos com 5 anos tinha os elementos de ser criativo. Mas com o tempo eles foram crescendo, foi um estudo longitudinal, mas com 10 anos já baixou para $30 \%$ e logo com 31 anos, mais ou menos, cai para $2 \%$. Então, por que que está baixando a criatividade com o tempo? O objetivo é que os professores precisam intervir, de forma insubordinadamente, para impedir esta tendência descendente de criatividade nos estudantes. Precisamos, pois nem sempre os pais vão intervir. Então, é trabalho dos professores fazerem isso. Então, como fazemos isso? Há um número de maneiras de fazer isso na sala de aula. A maneira favorita de Bia, a nossa mãe, era fazer isso com os alunos do Ensino Fundamental através da literatura. Uma criança, ao ler um livro, chama a sua atenção. É fácil encontrar livros infantis sobre qualquer assunto. Aqui estão alguns bons livros sobre a Matemática. Eu já usei vários desses livros e temos muito mais também. Eu não sei se todos têm tradução em português, mas hoje deve ter. E tem alguns deles, que não são tecnicamente livros de Matemática, mas é sobre o menino que, quando ele estava dormindo, uma estante que estava no quarto caiu em cima dele e fez ele bem fininho, pequenininho. Então ele ficou em duas dimensões, praticamente. Então, na história, os pais dobram ele e mandam ele para a Califórnia, porque ele não pode entrar no avião, porque ele não consegue sentar na cadeira. Então é uma história que, se eu fosse ensinar, numa aula de Matemática para 3.o ano do Ensino Fundamental, eu já usaria esse livro para ensinar as dimensões. Então, esses são alguns exemplos. Mas, por que é tão importante conec-

apenas como risquinhos. A criança passa a desenhar o pássaro com muito menos detalhes, procurando aproximar-se do desenho do livro ou influenciada por ele. 
tar a sala de aula ao mundo real do aluno? 0 que nos faz acreditar que os nossos alunos não podem ser os indivíduos que avancem a nossa sociedade? Quando pensamos sobre os avanços na humanidade: os direitos humanos, a diplomacia, o debate pacífico, como limpar a água e o ar, mudanças ambientais, descobertas farmacêuticas, ciências e computação, tecnologia, nós devemos fornecer a oportunidade para eles. 0 que separa um especialista de um estudante? Como podemos guiar os alunos para novos níveis de talento? Todos os filósofos, cientistas, matemáticos, diplomatas e descobridores começaram como alunos. E essa é a mentalidade que todos os professores devem ter dos seus alunos. É por isso que temos nos Estados Unidos um movimento progressivo acontecendo agora, onde os estudantes são convidados a resolver problemas do mundo real, problemas que mesmo adultos especialistas podem não ser capazes de responder ainda. Por exemplo, esses são de vários níveis, também você não vai perguntar isso para uma criança de cinco anos, mas com o tempo você vai chegando a esse ponto. Sentando em uma mesa por seis horas seguidas nos ajudam a aprender, então podíamos fazer uma pesquisa, os alunos poderiam fazer uma pesquisa desta, criar todos os padrões e o que se precisava saber e podiam fazer a sua própria pesquisa na sala de aula. Como podemos fornecer mais água limpa para as pessoas do mundo? Como podemos conectar ideias e comunicação ao redor do mundo? Como podemos criar casas mais ecológicas e com custos mais eficientes para mais pessoas? Como podemos mudar um país de terceiro mundo para um país de primeiro mundo? Como podemos ensinar as famílias a serem fisicamente mais responsáveis? É possivel termos uma saúde universal com alta qualidade e a baixo custo? Quanto anos temos ainda na terra antes de destruirmos todos os ecossistemas? Quais são as nossas alternativas? Quando os estudantes são convidados a responder os problemas do mundo real não há nenhuma resposta certa ou errada que o professor tenha predeterminado. 0 professor espera que os alunos descubram as ferramentas e habilidades que precisam para desenvolver suas ideias e que o aluno colabore e pesquise para encontrar uma solução. Ver o que eles aprendem em sala de aula, aplicado ao mundo real, anima os alunos, tornando-os desejosos de aprender mais e ajuda-os no caminho de amar, não apenas a Matemática, mas também a aprendizagem em geral. A escola não é um lugar para aprender o que nós adultos já sabemos, mas um lugar onde os alunos aprendem as habilidades necessárias para descobrir o desconhecido. Muito obrigada. (Gabriela e Rafaela, narrativa oral, ICOCIME 1, 2017)

No encerramento do segundo ICOCIME, do mesmo modo houve um momento de homenagem a Bia. Celi elaborou um texto com o objetivo de destacar e justificar algumas características pessoais:

Bondade
Elegância
Amor
Ternura
Respeito
Inteligência
Zelo

A todo momento nós falamos aqui de Beatriz Silva D'Ambrosio. Criar um acróstico, assim nomeado na língua portuguesa, com as primeiras letras do nome dela fica relativamente fácil, devido às inúmeras qualidades de Beatriz. A bondade era sua principal característica, uma característica que conduzia a constantes práticas de solidariedade, fraternidade e compaixão. Sua elegância não se restringia à aparência fisica, mas se fazia presente no convívio humano, tanto na vida pessoal quanto profissional. Havia sempre uma forma delicada de comunicar uma ideia, de fazer uma comunicação, de provocar uma reflexão, oralmente ou textualmente. Beatriz, sempre de forma constante, expressou seu amor pela vida e pelo ser humano. Sua sensibilidade em perceber o sofrimento, a angústia e a dificuldade de quem estivesse ao seu lado era excepcional. Suas expressões eram meigas em seu contato com as crianças e com seus estudantes. Havia sempre ternura em suas ações educativas, que logicamente não se restringia apenas a sua sala de aula. Quem convivia mais próximo dela sabia que o seu olhar e o seu sorriso manifestavam seu carinho, sem precisar expressar qualquer palavra. 0 respeito à vida humana e à natureza marcava seu coti- 
diano. Adorava admirar paisagens, lindas flores, lindas aves e se encantava com as cores e as suas formas de vida. Na casa em que vivia era um grande vidro que tinha na sala e ela gostava de sentar à mesa e olhar a paisagem e o quintal era aberto. Então tinha raposa, tinha os veadinhos e ela admirava os pássaros. Tinha um pica-pau que sempre ficava lá e ela dizia assim: "se um dia eu sair dessa casa, eu vou sentir muita falta disso. É o que eu mais gosto nessa casa". Sua inteligência era vivaz e criativa. Sua capacidade de estabelecer relações e provocar a reflexão do outro contribuiu para o desenvolvimento de muitas pessoas, tanto seus alunos, amigos e familiares. Tinha uma habilidade ímpar de problematizar uma situação e também de encontrar diversas soluções para o mesmo problema. Beatriz era sempre muito preocupada com o próximo. Tinha uma atenção especial a qualquer pessoa que the solicitasse ajuda. O zelo com a família, os amigos e seus alunos era excepcional. Nossa querida Beatriz, simplesmente Bia, nos deixou em um momento de vida de muita maturidade, tranquilidade, serenidade e muita alegria. Eu tive o privilégio de estar muito próxima a ela em seus últimos meses de vida aqui na Terra. E afirmo a vocês que ela estava muito feliz. Viajamos muito, fomos a Seattle, ao Alasca, a Portland, à Itália e à Grécia. Nosso relacionamento profissional nos permitiu vivenciar uma amizade muito bonita. Nos descobrimos com várias afinidades. Nossas ideias se complementavam nas atividades de escrita dos nossos textos. Trocávamos ideias apaixonantes com a insubordinação criativa. Sua luz permanecerá sobre nós, como pudemos vivenciar aqui estes dias. Ela deixou um legado de ensinamentos, de ideias e de provocações, que irão estimular a elaboração de novos estudos, como vimos aqui acontecendo. Essa educadora matemática especial, que deixa para as crianças e professores pesquisadores um exemplo de que para aprender, ensinar e pesquisar é preciso ética, respeito, solidariedade, compaixão e sensibilidade. Agradeço a Deus por ter me concedido o privilégio de conviver com Bia e a cada um de vocês por compartilhar do mesmo carinho que nos fez estar presentes neste evento e nos agraciou com essa presença. (LOPES, narrativa oral, ICOCIME 2, 2019)

\section{Dialogando com colaboradores e} bia

Fica evidente nas falas de Celi, das filhas e de tantos outros profissionais que conviveram com Bia que a insubordinação criativa não constava apenas nos seus textos e nos seus discursos. A insubordinação criativa estava presente em sua prática como professora e como pesquisadora, na sua vida e na essência de suas atitudes. Bia preocupava-se muito com o aprendizado das crianças e com a formação delas como cidadãos críticos, éticos e responsáveis pela melhoria da sociedade em que vivem. Nesta seção traremos, também, um pouco da produção bibliográfica de Bia acerca da insubordinação criativa ${ }^{4}$.

O conceito de insubordinação criativa é particularmente apropriado a esta educadora, pois atende às suas crenças e à esperança de construção de uma sociedade mais justa e digna para todos, em que a escola e a Educação Matemática priorizem a formação de cidadãos capazes de visualizar e construir esta sociedade. Isso vai exigir do professor postura reflexiva sobre si e sobre o contexto em que está inserido; atenção para identificar situações que se contrapõem aos princípios éticos, morais e de justiça social; criatividade e ousadia para tomar decisões não contempladas em regras preestabelecidas. Por isso Bia preocupava-se com a formação desses professores:

Nós preparamos professores que não têm voz e seguem sem crítica às regras, sem considerar se são boas ou se levarão ao bem das crianças. Preparamos líderes educacionais para defender políticas e documentos, em vez de defender seus professores e as crianças em seus sistemas. Esperamos que os professores sigam cegamente as políticas, sem se preocupar com o impacto de seus atos de ensinar sobre as crian-

4 A produção bibliográfica de Beatriz sobre insubordinação criativa é apresentada, com mais detalhes, no texto que se encontra nos anais do ICOCIME 2. Disponivel em: http://icocime.com/index.php/en/. 
ças, nem com o impacto de seus ensinamentos no quadro maior de contribuição para uma geração inspirada a trabalhar em direção a uma nova ordem mundial. (D'AMBROSIO, 2014, p. 5, tradução nossa)

Apresenta ainda algumas considerações sobre o que entende ser a função da escola e dos professores. Há equívocos evidenciados por Bia que nos levam a significativas reflexões:

Alguns podem argumentar que valores, ética, moral e solidariedade são ensinados em casa e não são da conta das escolas. Eu discordo. Não está correto ensinar amor e respeito em casa e viver em uma sala de aula de racismo e intolerância na escola. Não está correto saber que você pode ser o que quer que seja em casa, mas aprender na escola que nunca alcançará seus sonhos, já que todos os sistemas estão prontos para você nunca deixar as faixas mais baixas da escola e para que seus sonhos e aspirações possam ser silenciados e esmagados. 0 alinhamento das experiências de uma criança para garantir que ela atinja todo o seu potencial tem que estar em vigor em todos os aspectos da nossa sociedade - incluindo as experiências na escola. Na sala de aula de matemática não estamos lidando com soluções criativas de problemas, nem com valores. Em vez disso, estamos focados em fornecer um currículo nacional - o mesmo currículo que está em vigor há quase 200 anos. (D'AMBROSIO, 2014, p. 4-5, tradução nossa)

A preocupação com a formação plena das crianças é muito presente nos textos e nas atitudes de Bia. Ela não acreditava que a escola devesse se ocupar apenas do conhecimento científico e escolarizado, proporcionando uma formação fragmentada. Defendia uma educação plena, crítica e libertadora. Para ela o sucesso em Matemática toma, como eixos centrais no fazer matemático, a problematização, a escuta aos estudantes e o incentivo e o desenvolvimento de sua criatividade. Por isso admitia que a insubordinação criativa tem um papel muito importante na postura e nas tomadas de decisão de professores e de gestores escolares, possibilitando-lhes ajudar os seus alunos a se tornarem cidadãos não conformados e não submissos a regras e a códigos que violem a dignidade humana.

Ademais, seguindo as publicações de Bia e os relatos de profissionais que com ela trabaIharam, a pesquisa em Educação Matemática também apresenta indícios de insubordinação criativa e pode se beneficiar muito deste conceito. Segundo Bia, a insubordinação criativa de pesquisadores ocorre quando esses rompem com posições metodológicas rígidas, contraproducentes, burocráticas ou incoerentes.

Quando criam novas alternativas, afastam-se dos tradicionais critérios de excelência, consideram novos e apropriados critérios para avaliar o trabalho de seus pares e repensam sua posição de pesquisadores. Quando abandonam qualquer possibilidade de sentir-se como as fontes de todo o conhecimento, enquanto produzem ou supervisionam atividades de pesquisa. (D'AMBROSIO; LOPES, 2015b, p. 255, tradução nossa)

O rigor deve considerar o compromisso de gerar avanços nas pesquisas, de atender às diferentes visões sobre uma mesma realidade ou contexto e, sobretudo, de ter o participante ou colaborador da pesquisa como coautor na produção do conhecimento.

Atitudes insubordinadas criativamente requerem reflexão sobre as próprias ações e contextos, rupturas com o que está posto e superação dos paradigmas previamente determinados e das trajetórias metodológicas já percorridas. Para isso, professores e pesquisadores precisam desenvolver a autonomia como um processo contínuo de descobertas e transformações da própria prática educativa e investigativa. Igualmente necessária é a criatividade, entendida como a capacidade humana de inovar e estabelecer algo novo. $E$ é importante direcioná-la para ações positivas, em prol do bem-estar humano, de forma a 
não comprometer a ética e o respeito ao outro (D'AMBROSIO; LOPES, 2015).

Pesquisadores e professores são encorajados a ser coerentes com suas crenças e práticas profissionais e, ao mesmo tempo, respeitar as práticas de seus pares, suas opções teóricas e metodológicas, apresentando respeitosamente críticas construtivas qualitativamente para a área da Educação Matemática. Bia alerta que é preciso ter sensibilidade para entender o outro e o contexto em que está inserido, honrar o compromisso assumido no exercício das atividades diárias, mobilizar saberes de forma a proteger a integridade dos estudantes e dos espaços formativos, neutralizar os efeitos desumanizadores da autoridade burocrática.

E, finalmente, fica muito clara a importância significativa dada ao outro, quer seja ele estudante, colega, professor, pesquisador, não importa. Devemos ouvi-lo, conhecê-lo e entendê-lo, para que possamos atender aos seus anseios, compreender seus processos, ajudá-lo a superar seus medos e insuficiências. Em suma, acolhê-lo e complementá-lo naquilo que the falta ou que nos é solicitado.

\section{Referências}

BRIÃO, Gabriela Felix. Entrevista: conversa com a educadora matemática Beatriz D’Ambrosio: uma construtivista radical. e-Mosaicos - Revista Multidisciplinar de Ensino, Pesquisa, Extensão e Cultura do Instituto de Aplicação Fernando Rodrigues da Silveira (CAp-UERJ). Rio de Janeiro, RJ, v. 4, n. 7, p. 2-13, jun. 2015.

CLANDININ, D. Jean; CONNELlY, F. Michael. Pesquisa narrativa: experiências e história na pesquisa qualitativa. Tradução: Grupo de Pesquisa Narrativa e Educação de Professores. ILEEL/UFU, Uberlândia: EDUFU, 2011.

D'AMBROSIO, Beatriz Silva. Living contradictions: Negotiating practices as mathematics teacher educators. In: Annual Meeting of the Association of Ma- thematics Teacher Educators, 2014. Disponivel em: http://amte.net/sites/default/files/ living-contradictions-dambrosio-amte-2014.pdf Acesso em: 12 jun. 2019.

D'AMBROSIO, Beatriz Silva; LOPES, Celi Espasandin. Trajetórias profissionais de educadoras matemáticas. Campinas, SP: Mercado de Letras, 2014. (Coleção Insubordinação Criativa).

D'AMBROSIO, Beatriz Silva; LOPES, Celi Espasandin. Insubordinação criativa: um convite à reinvenção do educador matemático. Bolema: Boletim de Educação Matemática, Rio Claro, SP, v. 29, n. 51, abr. 2015a. Disponivel em: https://www.periodicos. rc.biblioteca.unesp.br/index.php/bolema/issue/ view/986 Acessado em: 15 set. 2019.

D'AMBROSIO, Beatriz Silva; LOPES, Celi Espasandin. Sowing new and rare seeds in Mathematics Education. In: D'AMBROSIO, Beatriz Silva; LOPES, Celi Espasandin. Creative Insubordination in Brazilian Mathematics Education Research, Raleigh, NC: Lulu Press, 2015b. p. 253-259.

DOMINICÉ, Pierre. O processo de formação e alguns dos seus componentes relacionais. In: NOVOA, A.; FINGER, M. 0 método (auto)biográfico e a formação. Tradução: Maria Nóvoa. 2. ed. Natal, RN: EDUfRN, 2014. p. 77-90.

DOSSE, François. 0 desafio biográfico: escrever uma vida. Tradução: Gilson César Cardoso de Souza. São Paulo: EDUSP, 2015.

FERRAROTTI, Franco. História e histórias de vida. O método biográfico nas ciências sociais. Tradução: Carlos Eduardo Galvão, Maria da Conceição Passeggi. Natal, RN: EDUFRN, $2014 a$.

FERRAROTTI, Franco. Sobre a autonomia do método biográfico. In: NOVOA, António; FINGER, Matthias. 0 método (auto)biográfico e a formação. Tradução: Maria Nóvoa. 2. ed. Natal, RN: EDUFRN, 2014b. p. 2956.

First International Conference on Creative Insubordination in Mathematics Education - ICOCIME 1. Universidade Cidade de São Paulo, São Paulo, 2017. 
LANI-BAYLE, Martine. Histórias de vida: transmissão intergeracional e formação. In: PASSEGGI, M. C. Tendências da pesquisa (auto)biográfica. Natal, RN: EDUFRN; São Paulo: Paulus, 2008. p. 297-316.

PASSEGGI, Maria da Conceição; SOUZA, Elizeu Clementino de. O movimento (auto)biográfico no Brasil: esboço de suas configurações no campo educacional. Investigación Cualitativa, v. 2, n. 1, p. 6 - 26, 2017. Disponivel em: https://ojs.revistainvestigacioncualitativa.com/index.php/ric/article/view/56 Acessado em: 15 set. 2019.
PUJADAS MUÑOZ, Joan Josep. El método biográfico: el uso de las historias de vida en ciencias sociales. La Rioja: Centro de Investigaciones Sociológicas (CIS), 1992.

The Second International Conference on Creative Insubordination in Mathematics Education - ICOCIME 2. Universidade Federal de Santa Catarina, Florianópolis, SC, 2019.
Enviado em: 20.10 .2019

Aprovado em: 21.03.2020

Josâne Geralda Barbosa é doutoranda em Ensino de Ciências e Matemática, na Universidade Cruzeiro do Sul. Trabalha no Instituto Federal de Minas Gerais (IFMG) - campus Ouro Preto, como Técnica em Assuntos Educacionais. Membro do grupo de pesquisa Educação, Trabalho e Sociedade, vinculado ao Instituto Federal de Educação, Ciência e Tecnologia Campus Ouro Preto. E-mail: josane.barbosa@ifmg.edu.br.

Celi Espasandin Lopes é doutora em Educação. Professora Titular do Programa de Pós-Graduação em Ensino de Ciências e Matemática na Universidade Cruzeiro do Sul (UNICSUL) e do Programa de Pós-Graduação em Educação na Universidade Cidade de São Paulo (UNICID). Coordenadora do Centro de Estudos e Pesquisas em Educação Matemática e Estatística (CEPEME). Líder do Grupo de Estudos e Pesquisas em Educação Estatística e Matemática (GEPEEM) e do grupo Práticas Pedagógicas na Educação Básica (PRAPEB). E-mail: celi.espasandin.lopes@gmail.com. 